\title{
Squamous Cell Carcinoma of the Pancreas with Massive Invasion of the Retroperitoneum
}

\author{
Hideyasu NaKashima, Tomihiro Hayakawa, Makoto Hoshino, Yasutaka KamiYa, Hirotaka OHara, \\ Tamaki Yamada, Kiyoshi Mizuno, Takanori InagaKi, Takahiro NaKaZAwa, Hisashi Yamada, \\ Makoto MIYAJI and Toshihiko TAKEUCHI
}

\begin{abstract}
A 79-year-old woman with a rare form of pancreatic carcinoma with massive invasion of the retroperitoneum presented with upper abdominal pain and vomiting. Although examination (computed tomography, barium enema, upper gastrointestinal series) suggested peritonitis carcinomatosa due to pancreatic cancer, a primary lesion of the pancreas was not confirmed by endoscopic retrograde pancreatography. Autopsy ultimately revealed a small tumor $(5 \times 8 \mathrm{~mm})$ of the uncinate process of the pancreas near the duodenum with peritonitis carcinomatosa. Microscopically, the tumor and its metastasis consisted of poorly differentiated squamous cell carcinoma without adenocarcinomatous change, a rare form of pancreatic tumor.
\end{abstract}

(Internal Medicine 34: 61-64, 1995)

Key words: pancreatic cancer, peritonitis carcinomatosa

\section{Introduction}

Squamous cell carcinoma is a rare form of pancreatic cancer that is derived from ductal cells, with most studies citing an incidence of about $0.5-2.0 \%$ (1-5). We report an unusual case of squamous cell carcinoma of the pancreas; a small tumor in the uncinate process close to the third portion of the duodenum had massively invaded the retroperitoneal region.

\section{Case Report}

A 79-year-old Japanese woman was referred to us with upper abdominal pain, vomiting, and a slight fever. She reported having epigastric discomfort and vomiting after meals intermittently for the previous 4 months. Her history revealed a cholecystectomy and choledocho-duodenostomy performed for gallstones 24 years earlier. She did not smoke or drink alcohol. Physical examination revealed a firm tender mass deep in the left upper quadrant of the abdomen. Ascites was absent. The remainder of the physical examination, including pelvic and rectal examination, was negative. Laboratory data revealed an increase in the white blood cell count to $10,100 / \mathrm{mm}^{3}$ and elevated serum levels of aspartate aminotransferase (50 U/1), alanine aminotransferase $(94 \mathrm{U} / \mathrm{l})$ and alkaline phosphtase $(1,777 \mathrm{U} / \mathrm{l})$. The serum level of elastase-1 was slightly in- creased, but the serum amylase level was normal. Tumor marker levels were normal except for Dupan-2. Serum levels of electrolytes and of blood urea nitrogen (BUN) were abnormal due to severe vomiting (Table 1). A chest X-ray showed no abnormality.

Ultrasonography showed mobile high-echogenic spots in the liver which suggested pneumobilia, but there was no tumor in the upper left quadrant of the abdomen. Computed tomography (CT) of the abdomen showed an irregularity around the third portion of the duodenum. The left kidney was surrounded by a thick area of low density (Fig. 1). An upper gastrointestinal series showed the presence of choledocho-duodenal anastomosis and a narrowed and irregular stenosis of the third portion of the duodenum (Fig. 2). Endoscopic retrograde pancreatography (ERP) revealed no abnormality of the main pancreatic duct nor branches of the uncinate process of the head of the pancreas (Fig. 3). Endoscopic findings showed marked stenosis in the third portion of the duodenum, but no malignant change was observed on the mucosal surface of that region. The catheter was easily passed through the stenotic area (Fig. 4) and no malignancy was apparent in the biopsy specimens obtained from that area. Barium enema showed segmental narrowing with spiculation in the transverse and descending colon (Fig. 5).

Even no abnormality was revealed on ERP, the clinical picture was considered consistent with a panreatic carcinoma

From the First Department of Internal Medicine, Nagoya City University Medical School, Nagoya

Received for publication June 6, 1994; Accepted for publication October 13, 1994

Reprint requests should be addressed to Dr. Tomihiro Hayakawa, the First Department of Internal Medicine, Nagoya City University Medical School, 1 Kawasumi, Mizuho-cho, Mizuho-ku, Nagoya 467 
NAKASHIMA et al

Table 1. Laboratory Data on Admission

\begin{tabular}{|c|c|c|c|}
\hline Urinalysis & Not particular & Blood chemistry & \\
\hline Stool occult blood & $(+)$ & $\mathrm{Na}$ & $130 \mathrm{mEq} / \mathrm{l}$ \\
\hline Peripheral blood & & K & $3.3 \mathrm{mEq} / \mathrm{l}$ \\
\hline White blood cell count & $10,100 / \mathrm{mm}^{3}$ & $\mathrm{Cl}$ & $79 \mathrm{mEq} / \mathrm{l}$ \\
\hline Red blood cell count 4 & $481 \times 10^{4} / \mathrm{mm}^{3}$ & $\mathrm{Ca}$ & $8.7 \mathrm{mg} / \mathrm{dl}$ \\
\hline Hemoglobin & $13.9 \mathrm{~g} / \mathrm{dl}$ & BUN & $40 \mathrm{mg} / \mathrm{dl}$ \\
\hline Hematocrit & $41.4 \%$ & Creatinin & $1.4 \mathrm{mg} / \mathrm{dl}$ \\
\hline Platelet & $34.1 \times 10^{4} / \mathrm{mm}^{3}$ & Uric acid & $11.7 \mathrm{mg} / \mathrm{dl}$ \\
\hline Serology & & Total protein & $7.1 \mathrm{~g} / \mathrm{dl}$ \\
\hline $\mathrm{C}$ reactive protein & $7.4 \mathrm{mg} / \mathrm{dl}$ & Albumin & $3.8 \mathrm{~g} / \mathrm{dl}$ \\
\hline \multicolumn{2}{|l|}{ Rheumatoid arthritis factor } & Total bilirubin & $1.1 \mathrm{mg} / \mathrm{dl}$ \\
\hline \multicolumn{2}{|l|}{ Treponema pallidum } & Direct bilirubin & $0.8 \mathrm{mg} / \mathrm{dl}$ \\
\hline \multicolumn{2}{|l|}{ hemagglutination test } & Alkaline phosphatase & $1,777 \mathrm{U} / 1$ \\
\hline \multicolumn{2}{|c|}{ Hepatitis B virus surface antigen $(-)$} & $\gamma$-glutamyl transpeptidase & $699 \mathrm{U} / 1$ \\
\hline \multicolumn{2}{|l|}{ Hepatitis C virus antibody } & Choline esterase & $245 \mathrm{U} / 1$ \\
\hline \multicolumn{2}{|l|}{ Tumor marker } & Aspartate aminotranspeptidas & ase $50 \mathrm{U} / \mathrm{l}$ \\
\hline & Alanine aminotranspeptidase & $94 \mathrm{U} / \mathrm{l}$ \\
\hline $\begin{array}{l}\text { Carcinoembryonic antigen } \\
\text { Carcinogenic antigen 19-9 }\end{array}$ & $-9<10 \mathrm{U} / \mathrm{ml}$ & Lactate dehydrogenase & $120 \mathrm{U} / \mathrm{l}$ \\
\hline Arphafetoprotein & $5 \mathrm{ng} / \mathrm{ml}$ & Creatinin phosphokinase & $16 \mathrm{U} / \mathrm{l}$ \\
\hline DUPAN-2 & $2,000 \mathrm{U} / \mathrm{ml}$ & Amylase & $259 \mathrm{U} / 1$ \\
\hline \multirow[t]{2}{*}{ Elastase-1 } & $480 \mathrm{ng} / \mathrm{ml}$ & Total cholesterol & $186 \mathrm{mg} / \mathrm{dl}$ \\
\hline & & Triglyceride & $124 \mathrm{mg} / \mathrm{dl}$ \\
\hline Chest X-P & Not particular & Glucose & $93 \mathrm{mg} / \mathrm{dl}$ \\
\hline Electrocardiogram & Not particular & Total bile acid & $4.7 \mu \mathrm{mol} / \mathrm{l}$ \\
\hline
\end{tabular}

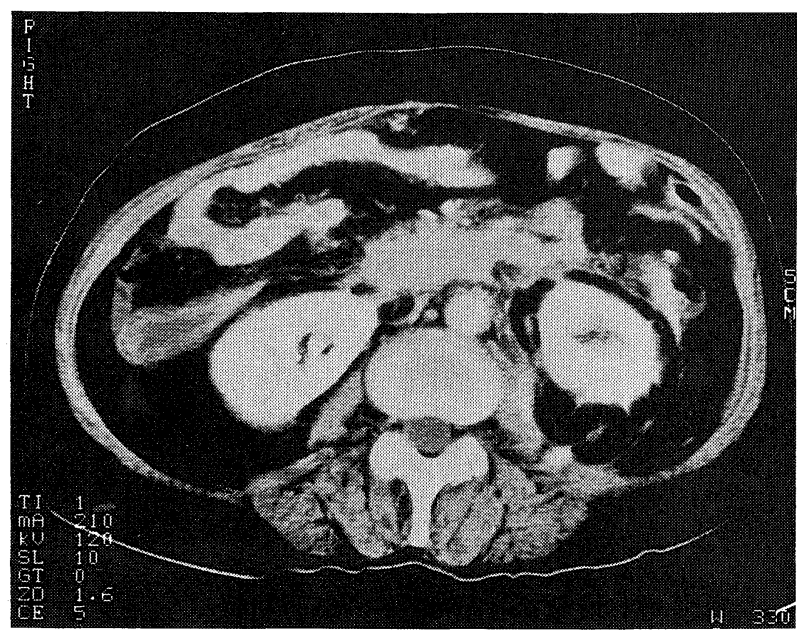

Fig. 1. Abdominal CT. Abdominal contrast CT showed irregularity around the third portion of the duodenum and an area of low density around the left kidney.

arising in the uncinate process and massively invading the retroperitoneum. The patient secreted $1,000 \mathrm{ml} /$ day of gastric juice and bile through a nasogastric tube, thus she was scheduled for a gastro-jejunostomy. However, as severe malignant invasion of the mesentery was found, only a gastrostomy could be performed. Examination of the biopsy specimen obtained from the mesentery intraoperatively revealed a squamous cell carcinoma. The patient subsequently developed numerous complications, including electrolyte disturbances from a persistent loss of gastric juice and bile, acute renal failure, and ultimately, heart failure. She died on the 44th hospital day.

Autopsy revealed a marked thickening of the mesentery and

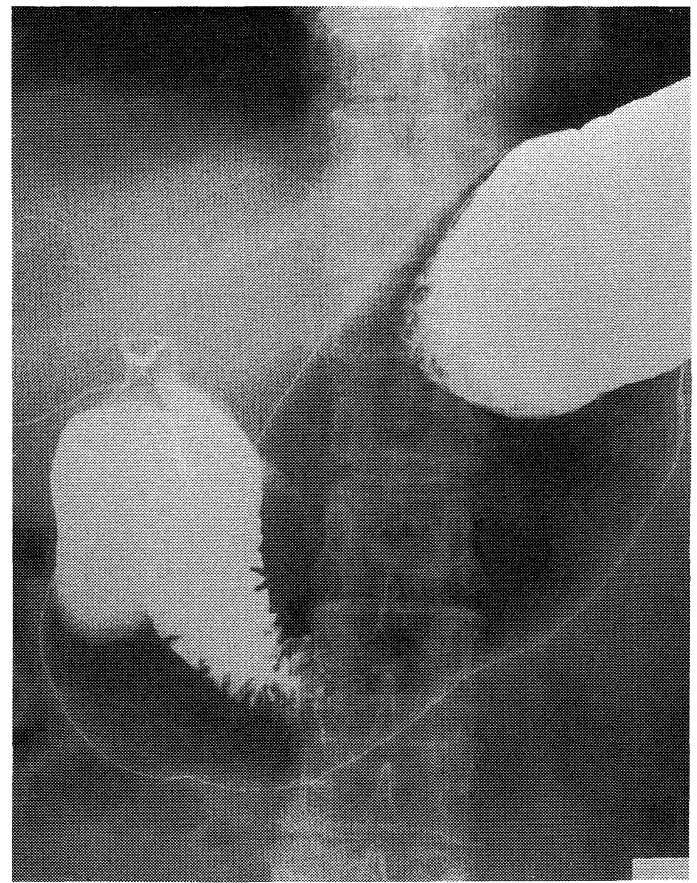

Fig. 2. Upper gastrointestinal series. An irregular stenosis of the third portion of the duodenum was found.

the retroperitoneum associated with progressive peritonitis carcinomatosa. No tumor was observed macroscopically in the uncinate process of the pancreas. The cut surface of the uncinate process, including the stenotic lesion of the duodenum, showed a small $(5 \times 8 \mathrm{~mm})$ whitish tumor very close to the markedly thickened duodenal wall (Fig. 6). The tumor was present at the 


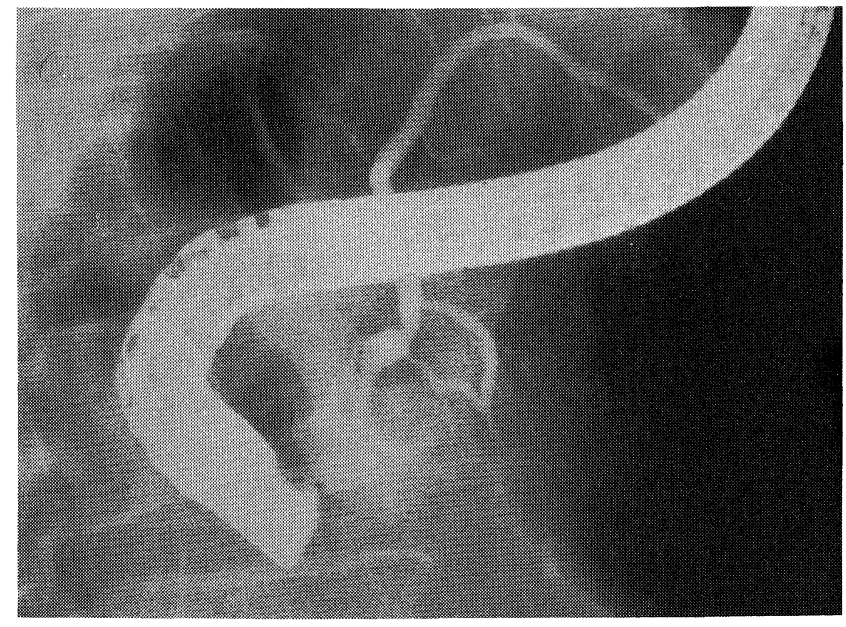

Fig. 3. Endoscopic retrograde pancreatography. Pancreatogram demonstrated the absence of abnormal findings on the main pancreatic duct and branches of the uncinate process.

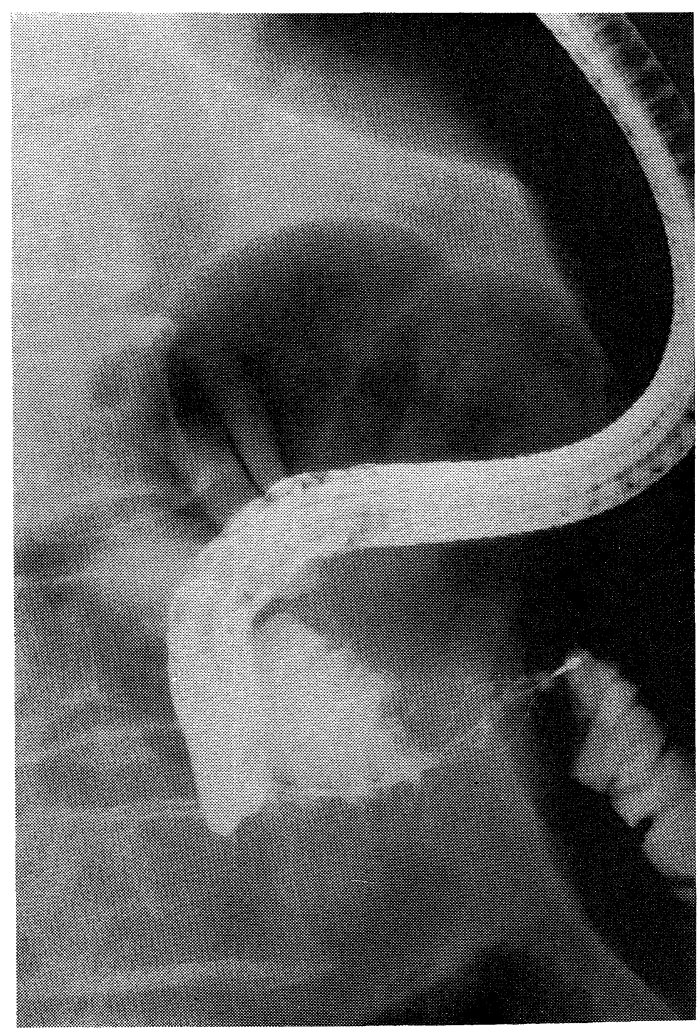

Fig. 4. Radiography of the duodenum. Basket catheter seems to pass easily through the stenosis of the third portion of the duodenum.

edge of the pancreatic tissue and had disrupted the muscular layer of the duodenum (Fig. 7). Histological examination revealed a poorly differentiated squamous cell carcinoma in the tumor and its metastasis (Fig. 8). Adenocarcinomatous component was not present. Malignancy was not found in the biliary tract, lung, urinary tract, ovary, uterus, or the other organs

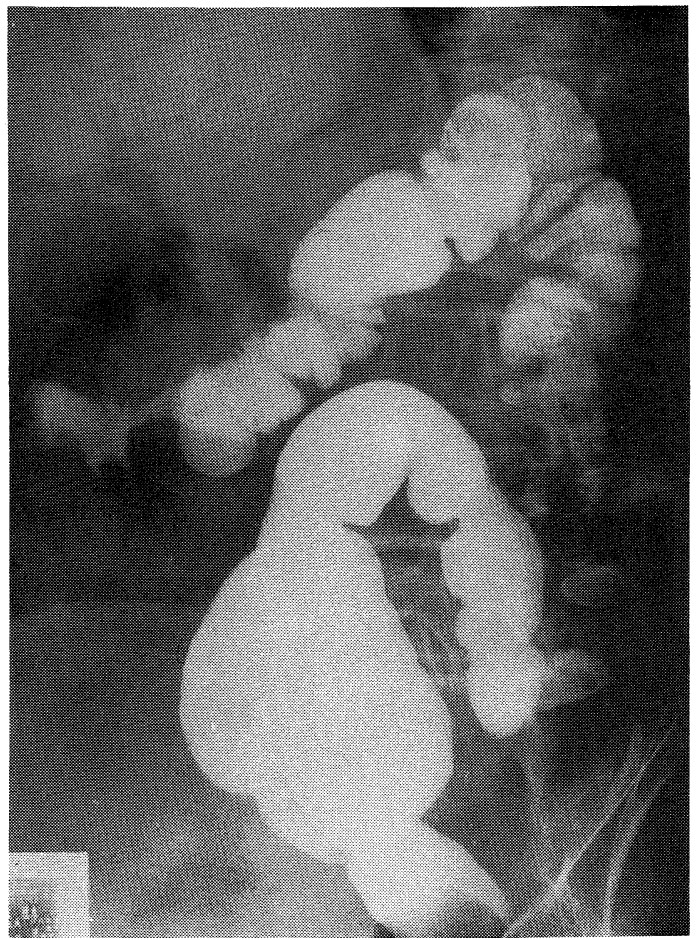

Fig. 5. Radiography of the colon. X-ray following barium enema showed irregular narrowing of the transverse and descending colon.

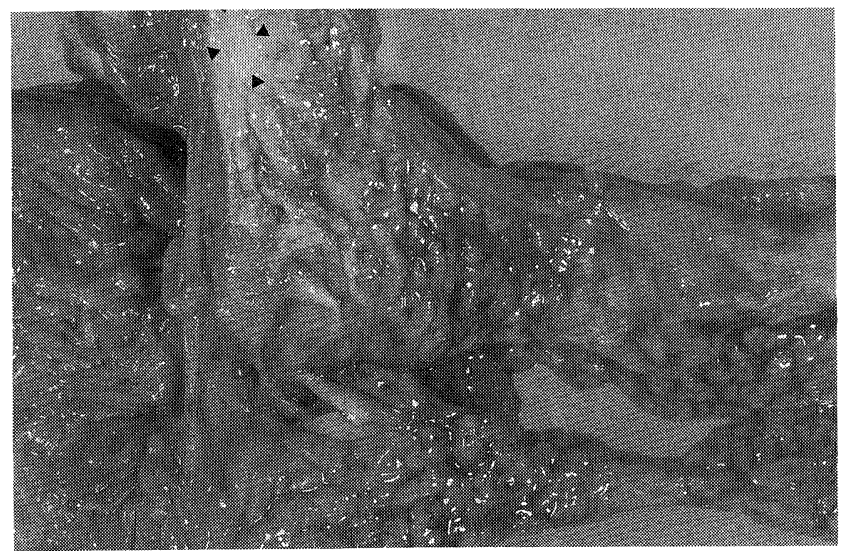

Fig. 6. The cut surface of the uncinate process of the pancreas. A small tumor $(5 \times 8 \mathrm{~mm})$ was found close to the duodenal wall.

examined.

\section{Discussion}

It was difficult to definitvely diagnose this case as pancreatic carcinoma before autopsy. Although the clinical picture and results of the various examinations all suggested peritonitis carcinomatosa due to pancreatic cancer, the ERP revealed no abnormality in the pancreas. Evidence obtained at autopsy was consistent with a diagnosis of primary squamous cell carcinoma of the pancreas. 


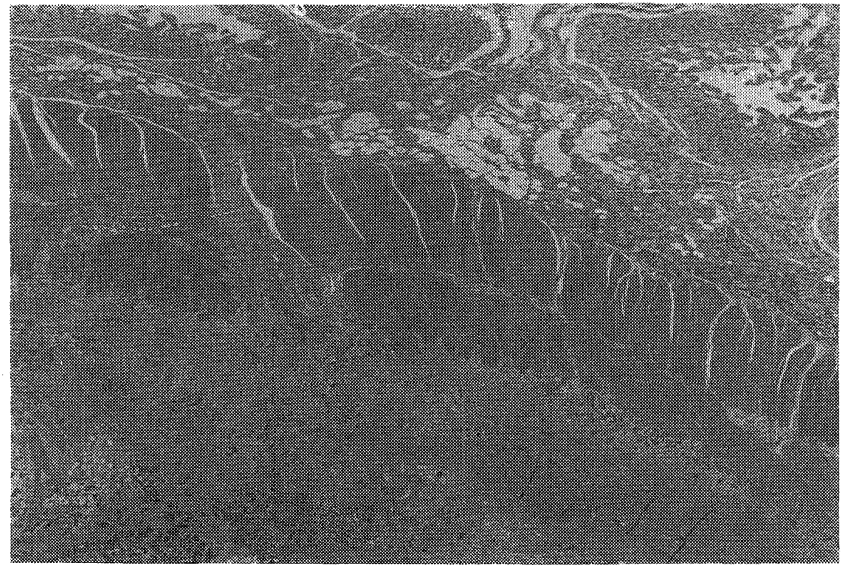

Fig. 7. Microscopic view $(\times 100)$. Tumor cells penetrated into the duodenal muscular layer.

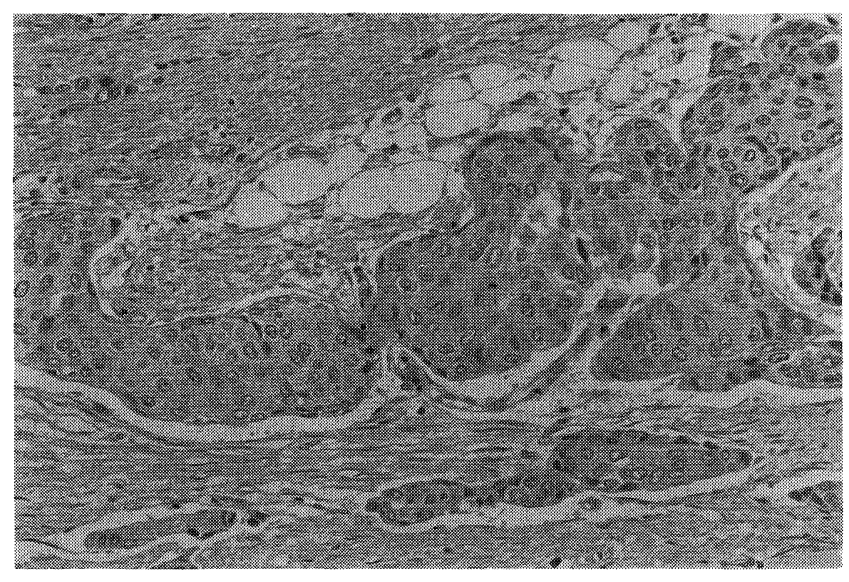

Fig. 8. Microscopic view $(\times 100)$. Poorly differentiated squamous cell carcinoma was demonstrated.

Squamous cell carcinoma is a relatively rare form of carcinoma of the pancreas. Of the 1300 cases of pancreatic cancers observed at autopsy in a survey in Japan (1992), only 9 cases $(0.7 \%)$ were squamous cell carcinomas (1). No cases of squamous cell carcinoma were found in the 1211 cases compiled by Saitou from registries for pancreatic cancer in Japan (1993) (2). Several reports cited an incidence of $0.5-1.9 \%$ (3-5). It is difficult to obtain a histological diagnosis of squamous cell carcinoma of the pancreas prior to either operation or autopsy. Sprayregen et al reported that hypervascularity and tumor brush in angiography are marked findings that distinguish squamous cell carcinoma from adenocarcinoma, in which the encasement and occlusion of arteries are generally observed (6). Saijou et al described a case of squamous cell carcinoma in which gallium scintigraphy revealed a hot area in the tumor (7). Enhancement of the tumor on contrast $\mathrm{CT}$ is characteristic of squamous cell carcinoma, according to Fajardo et al (8). Although several reports suggest that hypervascularity may be characteristic, we could not perform angiography in this case, because the patient was in poor condition. While most of the reported cases of squamous cell carcinoma with hypervascularity have shown a definite mass which was extrapancreatic in some cases (9-11), no mass was found on clinical examination in the present case. Autopsy revealed a small primary tumor with massive invasion of the retroperitoneum. Thus, in view of its growth pattern, the present patient had a rare form of pancreatic squamous cell carcinoma.

Although the histogenesis of a squamous cell carcinoma of the pancreas, whether alone or combined with adenocarcinoma, is not known, at least four theories have been suggested (1214); 1) a primitive cell capable of differentiating into either squamous or glandular carcinoma undergoes malignant change; 2) a preexisting adenocarcinoma undergoes squamous change; 3) a squamous metaplasia of the ductal epithelium undergoes a malignant formation; or 4) an aberrant squamous cell undergoes a malignant change. The tumor in this case was considered to be derived from aberrant squamous cells in the pancreas, because no metaplastic changes of the ductal cells were observed in the field near the carcinoma and no adenomatous changes were seen in either the carcinoma or the invading lesions.

\section{References}

1) Annual report of the pathological autopsy cases in Japan. edited by the Japanese Society of Pathology 34: 1438, 1992 (in Japanese).

2) Saitou $Y$. The investigation of registering carcinoma of the pancreas in Japan. Suizou 8: 559, 1993 (Journal of the Japan Pancreas Society).

3) Baylor SM, Berg JW. Cross-classification and survival characteristics of 5000 cases of cancer of the pancreas. J Surg 5: 335, 1973.

4) Miller JR, Baggenstoss AH, Comfort MW. Carcinoma of the pancreas: effect of histological type and grade of malignancy on its behavior. Cancer 4: 233, 1951.

5) Mikal S, Campbell AJA. Carcinoma of the pancreas: diagnostic and operative criteria based on 100 consecutive autopses. Surgery 28: 963, 1950.

6) Sprayregen S, Schoenbaum SW, Messinger NH. Angiographic features of squamous cell carcinoma of the pancreas. J Can Assoc Radiol 26: 122, 1975.

7) Saijou N, Maeda K, Kita S, et al. A case report of squamous cell carcinoma of the pancreas. Rinsho Houshasen 28: 313, 1983 (Japanese Journal of Clinical Radiology).

8) Fajardo LL, Yoshino MT, Chernin MM. Computed tomography findings in squamous cell carcinoma of the pancreas. J Comput Tom 12: 138, 1988.

9) Kamiya J, Ishiro $\mathrm{H}$, Inukai $\mathrm{O}$, et al. A case report of pancreatic adenosquamous carcinoma. Gan no Rinsho 28: 1674, 1982 (Japanese Journal of Cancer Clinics).

10) Tanno $S$, Obara $T$, Maguchi $H$, et al. A case of squamous cell carcinoma of the pancreas with prominent extrapancreatic growth. Nihon Shokakibyou Gakkai Shi 89: 2744, 1992 (Japanese Journal of Gastroenterology).

11) Sasaki J, Itou $\mathrm{H}$, Kasiwagi $\mathrm{S}$, et al. A case report of pancreatic adenosquamous carcinoma. Naika (Internal Medicine) 39: 337, 1977.

12) Tanaka $H$, Nisiguti $Y$, Satake $K$, et al. A case report of pancreatic adenosquamous carcinoma with difficult preoperative diagnosis. Suizou 1: 91, 1986 (Journal of the Japan Pancreas Society) (Abstract in English).

13) Kitagawa $T$, Ohta $T$, Aiba M, et al. Clinical study of 6 cases of pancreatic adenosquamous carcinoma. Suizou 5: 89, 1990 (Journal of the Japan Pancreas Society) (Abstract in English).

14) Ishikawa O, Matsui $Y$, Aoki I, et al. Adenosquamous carcinoma of the pancreas: A clinicopathologic study and report of three cases. Cancer 49: $1192,1980$. 